\title{
Emergency Medical Services amid New Wave of Coronavirus Disease 2019 Outbreak in Khon Kaen, Thailand
}

\author{
Korakot Apiratwarakul ${ }^{1,6} \mathbb{D}$, Takaaki Suzuki ${ }^{2}$, Ismet Celebi $^{3}$ D, Somsak Tiamkao ${ }^{4} \mathbb{D}$, Vajarabhongsa Bhudhisawasdi ${ }^{1}$, \\ Dhanu Gaysonsiri ${ }^{5,6}$, Kamonwon lenghong $^{1,6 *}$ id \\ ${ }^{1}$ Department of Emergency Medicine, Faculty of Medicine, Khon Kaen University, Khon Kaen, Thailand; ${ }^{2}$ Department of \\ Emergency and Critical Care Medicine, University of Tsukuba Hospital, Tsukuba, Japan; ${ }^{3}$ Department of Paramedic, Gazi \\ University, Ankara, Turkey; ${ }^{4}$ Department of Medicine, Faculty of Medicine, Khon Kaen University, Khon Kaen, Thailand; \\ ${ }^{5}$ Department of Pharmacology, Faculty of Medicine, Khon Kaen University, Khon Kaen, Thailand; ${ }^{6}$ Integrated Emergency \\ Medical Services and Pre-hospital Care Research Group, Faculty of Medicine, Khon Kaen University, Khon Kaen, Thailand
}

Edited by: Sasho Stolesk Citation: Apiratwarakul K, Suzuki T, Celebi I, Tiamkao S, Bhudhisawasdi V, Gaysonsiri D, lenghong K. Emergency Medical Services amid New Wave of Coronavirus Diseas Outbreak in Kho Kan, Thalland. Open Access . Es Kergency care; Coronavirus disease 2019; Pandemics:

Emergency care *Correspondence: Kamonwon lenghong, Departmen of Emergency Medicine, Faculty of Medicine, Khon Kaen University, Khon Kaen, Thailand. E-mail: kamonwan@kku.ac.th Received: 28-Apr-202 Revised: 22-Jun-2021 Accepted: 24-Jun-2021

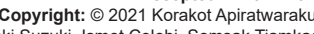
Tarabhongsa Bhudhisawasdi, Dhanu Gaysonsiri, Vajarabhongsa Bhy Ka Cenoni, Gaysonsin, Funding: This research did not receive any financial Competing Interest: The authors have declared that no competing interest exists Open Access: This is an open-access article distributed under the terms of the Creative Commons Attribution-

\begin{abstract}
BACKGROUND: Coronavirus disease 2019 (COVID-19) outbreaks occurring in many countries around the world have had a significant impact on emergency medical services (EMSs) in terms of the number of operations and procedures performed, including those on ambulances. However, the number of EMS amid the rising number of COVID-19 cases in Khon Kaen, Thailand, has not been well studied.

AIM: The aim of this study was to identify and analyze the relationship between the use of EMS and the outbreak of COVID-19.

METHODS: A cross-sectional study was done in Srinagarind Hospital, Khon Kaen, Thailand, with a single EMS centered. Data were collected between March 27, 2021, and April 9, 2021, and designated as day -7 to day 7 of pandemic services as well as normal services which collected data between March 27, 2019, and April 9, 2019 (day -7 to day 7 of normal services).

RESULTS: Three hundred and eight EMS operations were examined. A total of $77.9 \%(n=95)$ of pandemic services were for males and the mean age of the patients was $32.1 \pm 5.4$ years. During the normal services in 2019, the average number of EMS operations was $13.3 \pm 2.4$ times/day over the 2 weeks of the study. In 2021, before the outbreak (day -7 to day 1 ), the average number of EMS operations was $13.2 \pm 1.8$ times/day. After day 1 , there was a drop in the number of EMS operations which was associated with an increase in COVID-19 infections $(p<0.001)$

CONCLUSIONS: The number of EMS users during the COVID-19 outbreak decreased considerably compared to the pre-epidemic levels and normal service intervals, including the severity of the users, was more severe than normal.
\end{abstract}

\section{Introduction}

The coronavirus disease 2019 (COVID-19) outbreak have the devastating effects on the people daily life of many countries around the world. The rise in the number of patients has been directly linked to activities carried out in daily life without protection, spending time in crowded places, and adherence to social distancing policies. The impact on emergency medical services (EMSs) in terms of the number of operations performed, including those carried out on ambulances, has been significant. The previous studies have shown that the EMS members are well prepared for COVID-19 in protecting themselves from infection but that it is necessary to train them in the use of equipment [1], [2], [3]. EMS operations during the outbreak were quite different depending on the country. For example, a study in Denmark found $23.3 \%$ increase in calls to emergency services and that the duration of each talk increased from 2 min to $12 \min [4]$.

In Thailand, the EMS response time during the COVID-19 outbreak was also found shorter than for normal services and the number of non-urgency patients arriving to the emergency room dropped dramatically [5], [6]. In Turkey, there was $90.9 \%$ increase in calls to emergency services and $9.8 \%$ increase in EMS operations, among which there were suspected cases of COVID-19 in $15.2 \%$ of calls and $2.9 \%$ were actually diagnosed with the infection [7]. However, studies have shown that only $67 \%$ of EMS personnel are wearing personal protective equipment to levels of recommended safety [8]. In addition, studies have shown that the panic of infection among EMS personnel has increased, which is associated with increased risk of transmission to their family members [9]. In Israel, $8.51 \%$ of emergency calls were COVID-19 related, resulting in more than 4 times the typical use of emergency hotlines [10] similar to New York City [11] 
and Saudi Arabia [12]. A study in Japan found that the effects of this required hospitals allow for reduced delivery or increased coordination time in EMS [13].

Khon Kaen Province is located in the northeastern part of Thailand, $450 \mathrm{~km}$ from Bangkok with a population of 1.8 million. The Mueang district has a population of more than 400,000 people. As the first round of COVID-19 spread in early 2020, there were 13 cases discovered in Khon Kaen. Since then, the number of infections has been zero until early April 2021, when another COVID-19 outbreak occurred. Unlike previously, this time the number of cases was accompanied by medical personnel, resulting in panic in the community. The local administration cancelled all large events and closed crowded venues including restaurants, dental clinics, and bus stations. Therefore, a study of the relationship between the use of EMS amid the COVID-19 epidemic will be useful and can serve as a database for future planning to adjust service models during further outbreaks.

\section{Methods}

\section{Study design and setting}

The present study was a cross-sectional study. It was done in Srinagarind Hospital, Khon Kaen, Thailand, with a single EMS center. Data were gathered from the EMS database throughout 2019-2021. Ethical approval was provided by the Khon Kaen University Ethics Committee for Human Research (HE641221). The requirement for informed consent was waived since confidentiality protection had already been guaranteed. Accordingly, participants were not identified by name, but instead by a unique study number.

\section{Participants and data collection}

After ethical approval, we collected data of EMS in two periods:

1. Due to the latest COVID-19 outbreak in Khon Kaen Province which took place on April 3, 2021, the researcher set the date as day 1 , then retrieved data from 1 week prior and the ensuing week, thus collecting the data between March 27, 2021, and April 9, 2021, designated as day -7 to day 7 of pandemic services

2. The comparison period for normal services is to collect data between March 27, 2019, and April 9, 2019 (day -7 to day 7 of normal services).

After both groups of data were obtained, the EMS operations were converted to a research record form. The data with referrals from others hospitals and interfacility transfers were excluded from this study.

\section{Sample size and statistical analysis}

Based on the previous studies in a number of EMS operations during the COVID-19 pandemic [5], the sample size was calculated. To achieve a significance level of 0.05 , power of test of $80 \%$, and absolute precision 0.05355 , we determined that a sample size of 308 would be required. Statistical analysis was performed with Khon Kaen University license (SPSS Inc., Chicago, IL, USA) by IBM SPSS for Windows version 26.0. Categorical data were presented as percentages, with continuous data presented employing mean and standard deviation. Univariable analysis was carried out using a two samples t-test for numerical data and Pearson's correlation for data relationships between groups.

\section{Results}

Three hundred and eight EMS operations were examined over 2 weeks in April of 2021, during the latest COVID-19 pandemic in Khon Kaen, Thailand. When compared with the same period in 2019,122 (39.6\%) of which were in service during the pandemic period. The characteristics of the subjects and services are shown in Table 1. A total of $77.9 \%$ $(n=95)$ of those receiving pandemic services were male and the mean age of the patients was $32.1 \pm 5.4$ years. EMS operation times were most commonly performed during the afternoon shift (4:00 pm-11:59 pm) in both groups. The severity of patients' signs and symptoms according to the Thai Criteria Based Dispatch for EMS color code was red in $36.9 \%$ of cases, yellow in $57.4 \%$ of cases, and green in $5.7 \%$ of those seeking pandemic services.

During the normal or non-pandemic operation of services in 2019, the average number of EMS operations was $13.3 \pm 2.4$ times/day over the 2 weeks of the study. In 2021, before the outbreak (day -7 to day 1 ), the average number of EMS operations was $13.2 \pm 1.8$ times/day. After day 1, a steep drop in numbers of EMS operations can clearly be seen and is attributed to the increase in COVID-19 infections (Graph 1; $p<0.001$ ).

Table 1: Characteristics of the subjects

\begin{tabular}{llll}
\hline Characteristics & \multicolumn{2}{l}{$\begin{array}{l}\text { Normal services } \\
(\mathrm{n}=186)\end{array}$} & $\begin{array}{l}\text { Pandemic } \\
\text { services }(\mathrm{n}=122)\end{array}$ \\
\hline Age (years) mean \pm SD & $40.5 \pm 8.2$ & $32.1 \pm 5.4$ & $0.011^{*}$ \\
Gender: Male (\%) & $102(54.8)$ & $95(77.9)$ & $0.008^{*}$ \\
EMS operation time (\%) & & & \\
$\quad$ Morning shift & $68(36.6)$ & $52(42.6)$ & $0.010^{*}$ \\
$\quad$ Afternoon shift & $76(40.9)$ & $60(49.2)$ & \\
$\quad$ Night shift & $42(22.5)$ & $10(8.2)$ & \\
Severity with Thai Criteria Based Dispatch for EMS (\%) & & \\
$\quad$ Red & $25(13.4)$ & $45(36.9)$ & $0.004^{*}$ \\
$\quad$ Yellow & $54(29.0)$ & $70(57.4)$ & \\
$\quad$ Green & $107(57.6)$ & $7(5.7)$ & \\
\hline$\left(^{*}\right):$ Statistical significance, SD: Standard deviation, EMS: Emergency medical services. &
\end{tabular}




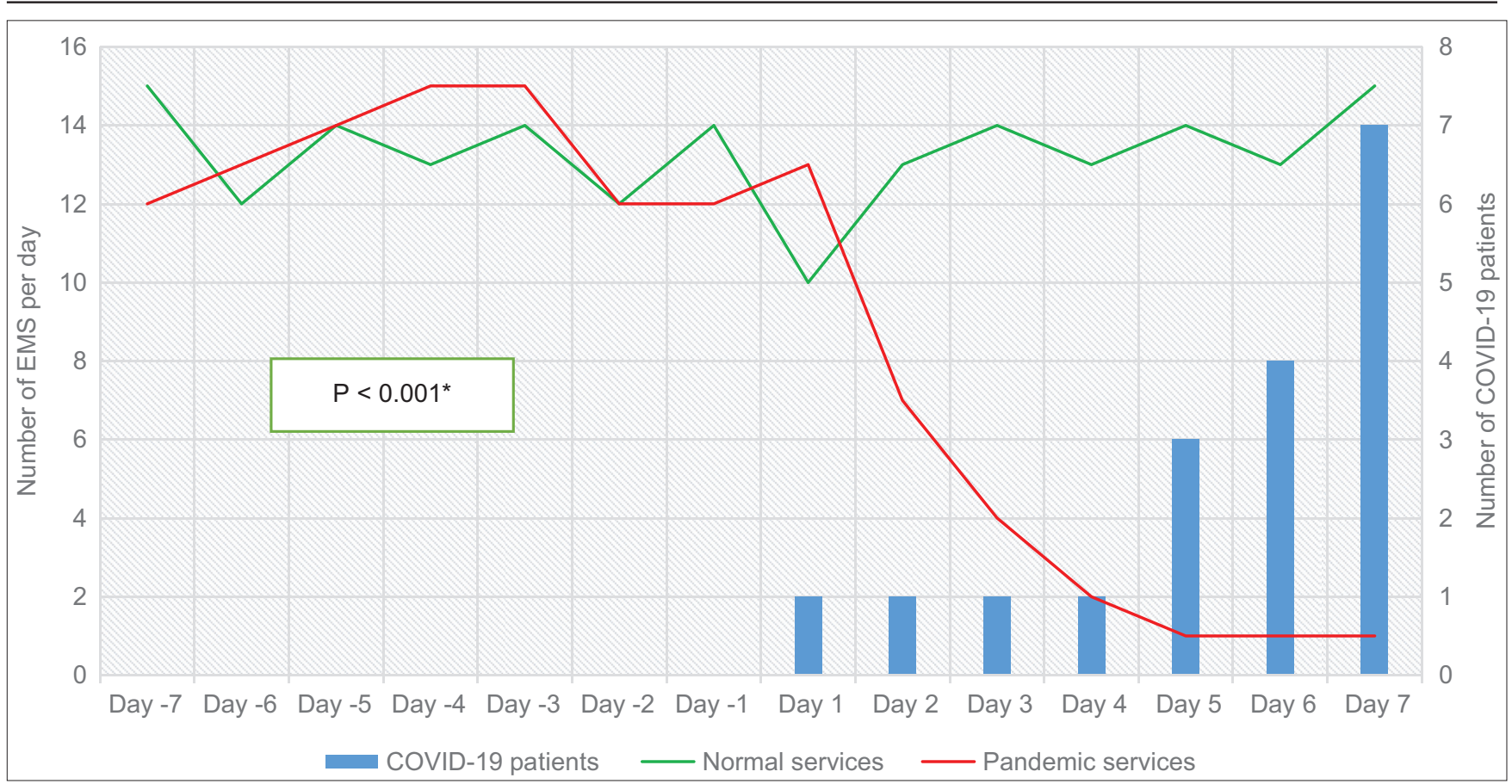

Graph 1: Number of EMS operations and number of COVID-19 patients. (*) Statistical significance

\section{Discussion}

This study examines the number and patterns of EMS usage after the most recent COVID-19 outbreak in Khon Kaen, Thailand. Thestudy was comparative to 1 week before the epidemic to form a baseline of information and 1 week after the epidemic. This was considered a panic phase because earlier outbreaks in the area had very little or close to zero infected patients, making the response to such situations different. In many countries, there is a significant increase in the use of EMS services, including phone calls, consultation, and an increasing number of operations [4], [7], [8], [9], [10], [11], [12]. However, in the areas studied, the amount of service usage dropped significantly with an average of 1-2 EMS operations per day as people were not willing to risk infection and stayed at home. Many did not want to travel to a crowded place such as a hospital, especially one where one of the medical personnel working there had been infected. This was consistent with the restaurant's closure and the number of service users at various bus stations, train stations, and airports which have dropped considerably despite the fact that this occurred during the period of Songkran Festival or the Thai New Year when millions of people are traveling back to their hometowns to spend time with family. Another reason may be that the number of infected people in the area is still low ( $<10$ cases/day), making the number of people close to the infected still very small. Therefore, calls for service and the number of EMS operations performed were also small. In addition, the public health system in Thailand also has a volunteer primary care unit to assess the symptoms of suspected infections and educate the community at the same time, resulting in a significant reduction in the number of EMS services.
The age of users during the outbreak was younger than the normal service period and mostly male. The first epidemic was more working age, resulting in increased male and younger users.

In terms of severity (Severity with Thai Criteria Based Dispatch for EMS), it was found that during most outbreaks service users were more severely symptomatic than at normal times, this was consistent with the previous studies which found that the amount of non-urgency patient cases decreased dramatically in the emergency department. Most of them are unwilling to come to the hospital as no one wants to risk infection. Thus, they wait until the symptoms are so severe, they have no choice but to use EMS [5], [6].

This study was limited due to the EMS center that collects the data not being the main command center of Khon Kaen Province, making it impossible to know the total number of telephone calls made to seek medical consultation or report symptoms. We suggest that other time periods and other important times of change be studied as well. In addition, retrospective data may result in incomplete information [14], [15], [16], [17].

\section{Conclusions}

The number of EMS users during the most recent COVID-19 outbreak was significantly less than the number of users during the same period preepidemic and in normal service intervals, additionally, the cases were much more severe than normal. 


\section{Acknowledgments}

The authors would like to express our sincere gratitude to Josh Macknick for acting as an English consultant.

\section{References}

1. Vatan A, Güçlü E, Öğütlü A, Kibar FA, Karabay O. Knowledge and attitudes towards COVID-19 among emergency medical service workers. Rev Assoc Med Bras (1992). 2020;66(11):15539. https://doi.org/10.1590/1806-9282.66.11.1553 PMid:33295409

2. Ardebili ME, Naserbakht M, Bernstein C, Alazmani-Noodeh F, Hakimi $\mathrm{H}$, Ranjbar $\mathrm{H}$. Healthcare providers experience of working during the COVID-19 pandemic: A qualitative study. Am J Infect Control. 2021;49(5):547-54. https://doi.org/10.1016/j. ajic.2020.10.001

PMid:33031864

3. Kovacs G, Sowers N, Campbell S, French J, Atkinson P. Just the facts: Airway management during the coronavirus disease 2019 (COVID-19) pandemic. CJEM. 2020;22(4):440-4. https:// doi.org/10.1017/cem.2020.353

PMid:32223782

4. Jensen T, Holgersen MG, Jespersen MS, Blomberg SN, Folke F, Lippert $F$, et al. Strategies to handle increased demand in the COVID-19 crisis: A coronavirus EMS support track and a webbased self-triage system. Prehosp Emerg Care. 2021;25(1):2838. https://doi.org/10.1080/10903127.2020.1817212 PMid:32870754

5. Apiratwarakul K, Songserm W, Bhudhisawasdi V, Wachirachiaranon $P$. Use of emergency medical services: Experience 100 days after first case of COVID-19. J Med Assoc Thai. 2021;104(Suppl 1):S5-7. https://doi.org/10.35755/ jmedassocthai.2021.S01.12123

6. Apiratwarakul $\mathrm{K}$, Kongudom $\mathrm{N}$, Kotruchin $\mathrm{P}$, Phungoen $\mathrm{P}$, Larthum K. Visits to the emergency department during the 2020 COVID-19 outbreak in Thailand. J Med Assoc Thai. 2021;104(Suppl 1):S1-4. https://doi.org/10.35755/ jmedassocthai.2021.S01.12122

7. Şan I, Usul E, Bekgöz B, Korkut S. Effects of COVID-19 Pandemic on emergency medical services. Int J Clin Pract. 2020;75(5):e13885. https://doi.org/10.1111/ijcp.13885 PMid:33280198

8. Murphy DL, Barnard LM, Drucker CJ, Yang BY, Emert JM,
Schwarcz L, et al. Occupational exposures and programmatic response to COVID-19 pandemic: An emergency medical services experience. Emerg Med J. 2020;37(11):707-13. https:// doi.org/10.1136/emermed-2020-210095

PMid:32958477

9. Usul E, Şan I, Bekgöz B. The Effect of the COVID-19 pandemic on the anxiety level of emergency medical services professionals. Psychiatr Danub. 2020;32(3-4):563-9. https://doi. org/10.24869/psyd.2020.563

PMid:33370767

10. Jaffe E, Sonkin R, Alpert EA, Magid A, Knobler HY. Flattening the COVID-19 curve: the unique role of emergency medical services in containing a global pandemic. Isr Med Assoc J. 2020;22(8):476-82.

PMid:33236579

11. Prezant DJ, Lancet EA, Zeig-Owens R, Lai PH, Appel D, Webber MP, et al. System impacts of the COVID-19 pandemic on New York City's emergency medical services. J Am Coll Emerg Physicians Open. 2020;1(6):1205-13. https://doi. org10.1002/emp2.12301 PMid:33392524

12. Al-Wathinani A, Hertelendy AJ, Alhurishi S, Mobrad A, Alhazmi $\mathrm{R}$, Altuwaijri $\mathrm{M}$, et al. increased emergency calls during the COVID-19 pandemic in Saudi Arabia: A national retrospective study. Healthcare (Basel). 2020;9(1):14. https:// doi.org/10.3390/healthcare9010014

PMid:33374453

13. Katayama Y, Kiyohara K, Kitamura T, Hayashida S, Shimazu T. Influence of the COVID-19 pandemic on an emergency medical service system: A population-based, descriptive study in Osaka, Japan. Acute Med Surg. 2020;7(1):e534. https://doi. org/10.1002/ams2.534

PMid:32685173

14. Ageta $\mathrm{K}$, Naito $\mathrm{H}$, Yorifuji $\mathrm{T}$, Obara $\mathrm{T}$, Nojima T, Yamada $\mathrm{T}$, et al. Delay in emergency medical service transportation responsiveness during the COVID-19 pandemic in a minimally affected region. Acta Med Okayama. 2020;74(6):513-20. https:// doi.org/10.18926/AMO/61210

PMid:33361871

15. lenghong K, Kleebbuakwan K, Apiratwarakul K, Phungoen $\mathrm{P}$, Gaysonsiri D, Bhudhisawasdi V. Comparison of cleaning methods for ultrasound probes at an emergency department in a resourcelimited country. J Med Assoc Thai. 2020;103(Suppl 6):67-71.

16. Apiratwarakul $K$, Songserm $W$, lenghong $K$, Phungoen $P$, Gaysonsiri D, Bhudhisawasdi V. The role of mechanical cardiopulmonary resuscitation devices in emergency medical services. J Med Assoc Thai. 2020;103(Suppl 6):98-101.

17. Apiratwarakul $K$, lenghong $K$, Gaysonsiri $D$, Mitsungnern $T$, Buranasakda M, Bhudhisawasdi V. The effectiveness of oxygen-powered inhalation devices in prehospital care. J Med Assoc Thai. 2020;103(Suppl 6):58-60. 